Article

\title{
Comparing the Bio-Hydrogen Production Potential of Pretreated Rice Straw Co-Digested with Seeded Sludge Using an Anaerobic Bioreactor under Mesophilic Thermophilic Conditions
}

\author{
Asma Sattar ${ }^{1, \dagger}$, Chaudhry Arslan ${ }^{1,2, \dagger}$, Changying Ji ${ }^{1, *}$, Sumiyya Sattar ${ }^{3}$, Irshad Ali Mari ${ }^{4}$, \\ Haroon Rashid ${ }^{2}$ and Fariha Ilyas ${ }^{5}$ \\ 1 College of Engineering, Nanjing Agricultural University, Nanjing 210031, China; \\ asma2005_2182@hotmail.com (A.S.); arslanakrampk@hotmail.com (C.A.) \\ 2 Department of Structures and Environmental Engineering, University of Agriculture, Faisalabad 38000, \\ Pakistan; haroon9a@gmail.com \\ 3 Veterinary Research Institute, Lahore Cantt 54810, Pakistan; sumiyyasattar@hotmail.com \\ 4 Khairpur College of Engineering and Technology Sindh Agriculture University, Khairpur Mir 66020, \\ Pakistan; irshad_mari@hotmail.com \\ 5 Department of Soil Science, Bahauddin Zakariya, University, Multan 60800, Pakistan; \\ aafma12345@hotmail.com \\ * Correspondence: chyji@njau.edu.cn; Tel.: +86-25-5860-6571 \\ + These authors contributed equally to this work.
}

Academic Editor: Tariq Al-Shemmeri

Received: 19 January 2016; Accepted: 8 March 2016; Published: 15 March 2016

\begin{abstract}
Three common pretreatments (mechanical, steam explosion and chemical) used to enhance the biodegradability of rice straw were compared on the basis of bio-hydrogen production potential while co-digesting rice straw with sludge under mesophilic $\left(37^{\circ} \mathrm{C}\right)$ and thermophilic $\left(55^{\circ} \mathrm{C}\right)$ temperatures. The results showed that the solid state $\mathrm{NaOH}$ pretreatment returned the highest experimental reduction of LCH (lignin, cellulose and hemi-cellulose) content and bio-hydrogen production from rice straw. The increase in incubation temperature from $37^{\circ} \mathrm{C}$ to $55^{\circ} \mathrm{C}$ increased the bio-hydrogen yield, and the highest experimental yield of $60.6 \mathrm{~mL} / \mathrm{g} \mathrm{VS}_{\text {removed }}$ was obtained under chemical pretreatment at $55^{\circ} \mathrm{C}$. The time required for maximum bio-hydrogen production was found on the basis of kinetic parameters as $36 \mathrm{~h}-47 \mathrm{~h}$ of incubation, which can be used as a hydraulic retention time for continuous bio-hydrogen production from rice straw. The optimum $\mathrm{pH}$ range of bio-hydrogen production was observed to be $6.7 \pm 0.1-5.8 \pm 0.1$ and $7.1 \pm 0.1-5.8 \pm 0.1$ under mesophilic and thermophilic conditions, respectively. The increase in temperature was found useful for controlling the volatile fatty acids (VFA) under mechanical and steam explosion pretreatments. The comparison of pretreatment methods under the same set of experimental conditions in the present study provided a baseline for future research in order to select an appropriate pretreatment method.
\end{abstract}

Keywords: bio-hydrogen production; pretreatments; kinetic parameters; volatile fatty acids; response surface methodology

\section{Introduction}

Global energy demand is rising due to the industrialization and population growth. As fossil fuels are the dominant source of energy, the heavy reliance on fossil fuels is not only depleting them, but also contributing to climate change. In order to overcome this issue, efficient utilization of alternative energy sources, such as biomass, solar, wind and hydro, are getting more and more attention. Among 
all renewable sources, biomass is becoming an auspicious alternative due to near-carbon neutrality and ample availability [1].

In China, 0.75 billion tons of biomass energy resources were generated during the year 2010, out of which $52 \%$ was crop residue. One of the major shareholders in crop residue was rice straw, contributing $62 \%$ of total crop residue resources. About 1.35 tons of rice straw are produced for every ton of rice grain harvested, resulting in 1.9 million tons of rice straw production at $15 \%$ moisture content $[2,3]$. Although rice straw is used as a fuel for domestic purposes, a part of animal feed and in the paper making industry, still, a huge quantity of rice straw is left useless in the field. The burning of leftover straw in the open field causes serious environmental issues. Therefore, converting the rice straw into more valuable products, like methane, ethanol and bio-hydrogen, not only solves the issue of rice straw management, but also addresses the energy challenges faced by the world in recent times. Such conversion can be done by thermo-chemical means, like combustion, pyrolysis or liquefaction, which are not environmentally-friendly techniques. The other option of converting rice straw into a valuable energy resource is biological means, which include anaerobic fermentation [4]. No doubt, this biological technique is environmentally friendly, but it requires a variety of substrates for converting biomass into biofuels, which makes it the most promising option for treating lignocellulosic materials $[5,6]$. In this regard, bio-hydrogen production along with bio-ethanol and methane through anaerobic fermentation have great potential to develop a sustainable energy production system. Hawkes et al. [7] reported that bio-hydrogen production from such agricultural waste is more advantageous over other fuels, as hydrogen-producing microorganisms could consume a wide range of sugar hydrolysates as compared to other microbes. These sugar hydrolysates are available in rice straw in the form of cellulose and hemicellulose, entangled by the lignin moieties, which hinder the biological degradation of sugar content in rice straw [8]. To overcome this issue, pretreatment of rice straw is required to break the crystallinity of cellulose and the lignin seal [9]. Commination of lignocellulosic biomass is a traditional pretreatment method which changes the ultrastructure of rice straw. In this technique, a final particle size of $0.2-2 \mathrm{~mm}$ is achieved, which increases the surface area and reduces the cellulose crystallinity for better biodegradability $[9,10]$. Steam explosion is another widely-opted pretreatment method in which lignocellulosic biomass is exposed to $160-260^{\circ} \mathrm{C}$ temperatures under 0.69-4.83 MPa for several seconds to a few minutes [11]. Under such conditions, hemicellulose is hydrolyzed into component sugars, and lignin is redistributed, which enhances the biodegradation process [12]. Although steam explosion and comminution are effective pretreatment techniques, still there is the need of a pretreatment technique that has less energy intake as compared to the techniques discussed above. In this regard, alkaline treatment is a simple and effective one, as it causes delignification, increases internal surface area and porosity, reduces crystallinity and the degree of polymerization and breaks down the links of polymers with lignin [13,14]. Apart from all these benefits, there are some environmental issues, like disposal and recycling of chemicals associated with alkaline treatment, which can be overcome by opting for solid state treatment instead of liquid state treatment [15]. Although $\mathrm{NaOH}, \mathrm{Ca}(\mathrm{OH})_{2}, \mathrm{KOH}$ and $\mathrm{NH}_{3} \cdot \mathrm{H}_{2} \mathrm{O}$ can be used for alkali treatment, $\mathrm{NaOH}$ is widely used for lignocellulosic biomass and especially for rice straw [13]. As a whole, much work has been done on different pretreatment methods, and every pretreatment method has its own merits and demerits under the tested conditions. It is difficult to compare the efficiency of these pretreatment methods from a review, as every study presented that the tested method is the optimum method for pretreating rice straw. Therefore, in order to address this issue, these methods need to be studied under similar conditions to compare the treatment efficiency, especially on the basis of bio-hydrogen production potential.

Bio-hydrogen production through anaerobic digestion cannot be done only with a pretreated rice straw, but also requires some source of microorganisms. In this regard, a mixed consortium of Clostridium is the best option, which is easily available in the form of sludge [16]. Although, sludge has some hydrogen consumers, like methanogens, along with hydrogen producers, which can be inactivated through heat treatment efficiently [17]. 
The following study was conducted to compare the effect of mechanical, thermal and chemical treatment on rice straw for bio-hydrogen production, co-digested with sludge under mesophilic and thermophilic conditions. The volatile solids, volatile fatty acids, soluble chemical oxygen demand and $\mathrm{pH}$ were also measured to observe different aspects of the fermentation process.

\section{Material and Methods}

\subsection{Pretreatment of Rice}

The rice straw was collected from Ba Bai Qiao experimental field of Nanjing Agricultural University, cut into short pieces and air dried. Later, three different pretreatments were performed on rice straw, i.e., mechanical, chemical and thermal. In the mechanical treatment, straw was ground in a grinder (LH-08B Speed Grinder, CNC Instruments Inc.: Zhejieng, China), passed through a 2-mm sieve, and sieved straw was used for bio-hydrogen production.

In order to perform chemical treatment, the solid state $\mathrm{NaOH}$ pretreatment proposed by He et al. [15] was opted after some modification. The straw was first chopped by a specially-designed chopper and then ground into $5 \mathrm{~mm}-10 \mathrm{~mm}$-sized particles. Later, $100 \mathrm{~g}$ of straw were mixed with $80 \mathrm{~g}$ of distilled water containing $6 \mathrm{~g}$ of $\mathrm{NaOH}$ and mixed thoroughly to make the resultant moisture content at $80 \%$ on a dry basis. Later, the straw was placed in a 1-L beaker for three weeks at room temperature. By the end of pretreatment, the straw was dried in an oven and stored in a refrigerator. The selected pretreatment has no environmental issues, and it does not require washing to remove leftover $\mathrm{NaOH}$.

The steam explosion was done by chopping the straw into 3-4 cm-sized particles [18]. On the basis of initial moisture content, water was added to the straw, so that the total solids (TS) level could be maintained around 20\% [19]. After adding water, straw was thoroughly mixed and left for $4-5 \mathrm{~h}$, so that water is absorbed by the straw uniformly. Later, the straw was added into the steam explosion chamber (2 L) till it was half filled and sealed from the top. The saturated steam was added into the chamber till the temperature of the chamber reached $240^{\circ} \mathrm{C}$, after which, the timing of the reaction was started. After $240 \mathrm{~s}$, the valve was opened, so that explosive depressurization could occur [20]. The resultant straw was collected and stored in bags.

\subsection{Seeded Sludge}

The sludge was obtained from a settling channel in Pokuo and was sieved and washed with tap water to remove dust and foreign materials [21]. Later, it was placed in a preheated oven at $100{ }^{\circ} \mathrm{C}$ for $30 \mathrm{~min}$ in order to deactivate hydrogenotrophic methanogens [22,23]. The volatile solids, volatile fatty acids, alkalinity and $\mathrm{pH}$ of the sludge were $2.87 \%, 13950 \mathrm{mg} / \mathrm{L}, 3700 \mathrm{mg} / \mathrm{L}$ and 7.1 , respectively.

\subsection{Anaerobic Bio-Reactor}

In the present study, a 20-L stainless steel double jacket anaerobic bioreactor was developed in collaboration with Zhejiang Instruments Limited (Figure 1). The reactor was equipped with a proportional integral derivative (PID) controller (CAN-C700, Aivpen Instruments, Le Qing, China) to manage temperature with the help of a heating unit and a platinum resistance temperature sensor (PT-100). The flow through heating unit was controlled by a solenoid valve (D01-4104, YuYao Sanlixin Solenoid valve Co.: Shanghai, China) and water circulation pump (UP Basic, Grundfos: Sozhou, China) connected to a 100-L water reservoir. The $\mathrm{pH}$ was managed by another PID $\mathrm{pH}$ controller (PH900, Acitek Instrumentsm: Shanghai, China), pH sensor (Easyferm plus 120, Hamilton Bonaduz AG: Bonaduz, Switzerland) and a peristaltic pump to add the desired amount of chemical from a 500-mL glass bottle to maintain $\mathrm{pH}$ at specific points. Thorough mixing was done by a three-stage stirrer connected to a permanent magnet DC servo motor (ZSD05A, Shanghai ShuDong Motor Co., Ltd.: Shanghai, China). There was an inlet port (1-inch diameter) for feeding materials at the top, and an outlet port (1-inch diameter) along with a ball valve was at the bottom. A vacuum pump (FY-1H-N, 
Zhejiang E \& M Value Co.: Zhejiang, China) was also attached to the reactor to develop anaerobic conditions $[24,25]$.

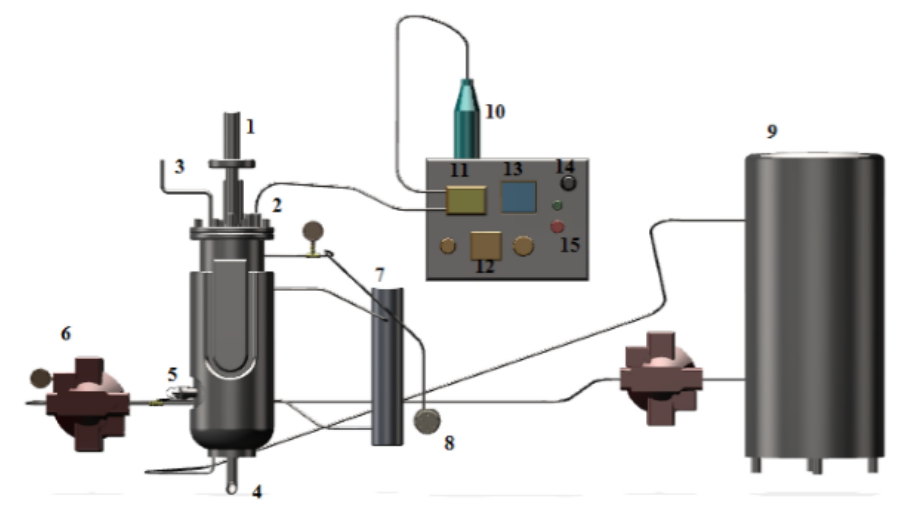

\footnotetext{
1-Stirring Motor, 2-Feeding Ports, 3-Gas Collecting Unit, 4- Outlet Port, 5- Temperature and pH Sensors

6- Water Circulation Pump, 7- Heating Unit, 8-Vacuum Pump, 9- Water Reservoir, 10- Chemical storage

11- Peristaltic Pump, 12- Temperature Controller, 13- pH Controller, 14- Stirrer Controller, 15- Power
}

Figure 1. Schematic diagram for the double jacket anaerobic bio-reactor.

\subsection{Analytical and Assay Methods}

The total solids (TS), volatile solids (VS), chemical oxygen demand (COD), volatile fatty acids (VFA) and alkalinity were measured by standard methods [26]. The volume of hydrogen gas was measured in the same way opted in our previous studies $[24,25,27]$. The compositional properties of straw were measured by the procedure opted by Ververis [28]. The bio-hydrogen production was modeled by the modified Gompertz equation for the determination of kinetic parameters [29]:

$$
\mathrm{H}=\operatorname{Pexp}\left\{-\exp \left[\frac{\mathrm{R}_{\mathrm{m}} \mathrm{e}}{\mathrm{P}}(\lambda-\mathrm{t})+1\right]\right\}
$$

where $\mathrm{H}, \mathrm{t}, \mathrm{P}, \mathrm{R}_{\mathrm{m}}, \lambda$ and e represent cumulative bio-hydrogen production $(\mathrm{mL})$, incubation time (h), bio-hydrogen production potential, maximum bio-hydrogen production rate $(\mathrm{mL} / \mathrm{h})$, lag phase duration (h) and 2.71828, respectively. The values of $\mathrm{H}, \mathrm{t}, \mathrm{P}$ and $\mathrm{R}_{\mathrm{m}}$ were solved by using the curve fitting tool in MATLAB (Ver. 2010 a).

In order to develop 2D plots through the response surface methodology, the full quadratic model as shown below was used to model the bio-hydrogen production, $\mathrm{pH}$ and volatile fatty acids [30,31]:

$$
\mathrm{Y}=a_{0}+\sum_{i=1}^{n} a_{i} X_{i}+\sum_{i=1}^{n} a_{i i} X_{i}^{2}+\sum_{i=1}^{n} \sum_{i<j=2}^{n} a_{i j} X_{i} X_{j}
$$

where $X_{i}$ and $X_{j}$ are the controlled parameters, which influence $Y$ and $a_{0}, a_{i i}$ and $a_{i j}$, are the offset term, linear and quadratic coefficients, respectively.

\subsection{Batch Experiments}

The plant was operated at $10 \%$ TS by adding pretreated straw and seeded sludge in equal proportions on a TS basis, and the initial $\mathrm{pH}$ was maintained to 7.5 with the help of $\mathrm{pH}$ controller using $3 \mathrm{M} \mathrm{HCl}$ or $3 \mathrm{M} \mathrm{NaOH}$ [18]. The co-digestion was done under mesophilic $\left(37^{\circ} \mathrm{C}\right)$ and thermophilic $\left(55^{\circ} \mathrm{C}\right)$ conditions, and all experiments were performed in duplicate [27]. The volume of bio-hydrogen and $\mathrm{pH}$ was measured after $12 \mathrm{~h}$-intervals, and VFAs were measured on a daily basis. The incubation time was set to 7 days, after which TS and VS were analyzed [32]. 


\section{Results and Discussion}

\subsection{Pretreatment Effect on Kinetic Parameters}

The bio-hydrogen production rate $\left(R_{m}\right)$ increased with an increase in temperature, and the intensity of increase was different under different pretreatments (Table 1). The maximum and minimum increase in the $R_{m}$ value due to the increase in temperature from $37{ }^{\circ} \mathrm{C}$ to $55^{\circ} \mathrm{C}$ was observed in steam explosion (12.56\%) and chemical pretreatment (4.39\%), respectively. On the other hand, the same increase in temperature increased the cumulative bio-hydrogen production (P) by $39.16 \%, 26.86 \%$ and $10.97 \%$ for chemical pretreatment, mechanical pretreatment and steam explosion, respectively. In the case of steam explosion, the increase in $\mathrm{P}$ and $\mathrm{R}_{\mathrm{m}}$ due to the increase in temperature was close, i.e., $10.96 \%$ and $12.56 \%$, respectively. However, in the case of chemical pretreatment, the difference in $\mathrm{P}$ and $\mathrm{R}_{\mathrm{m}}$ was much higher. The difference was observed due to the bio-hydrogen production period between two temperatures, i.e., bio-hydrogen production started after $12 \mathrm{~h}$ of incubation and continued till $120 \mathrm{~h}$ at $37^{\circ} \mathrm{C}$, whereas it started before $12 \mathrm{~h}$ of incubation and continued till $144 \mathrm{~h}$ at $55^{\circ} \mathrm{C}$ (Figure 2). As a whole, the increase in temperature from mesophilic to thermophilic increased the bio-hydrogen production, as reported by Alemehdi et al. [33] and Kim et al. [32]. The increase in hydrogen production might be due to the presence of Thermoanaerobacterium thermosaccharolyticum that grow at a higher temperature and produce more hydrogen [34]. On the other hand, due to the early start of bio-hydrogen production at $55^{\circ} \mathrm{C}$ under chemical pretreatment, there was a $550-\mathrm{mL}$ difference in the volume of gas produced between the two reactors under different temperatures that remained almost the same till $60 \mathrm{~h}$ of incubation. After $60 \mathrm{~h}$, the difference in bio-hydrogen production kept on increasing. This means that the $\mathrm{R}_{\mathrm{m}}$ for both temperatures was almost the same till $60 \mathrm{~h}$ of incubation, after which $\mathrm{R}_{\mathrm{m}}$ increased, which increased the value of $\mathrm{P}$ for thermophilic conditions (Figure 2), whereas such an impact of temperature can be observed in the studies reported by Leilei et al. [19] and Chen et al. [35]. A similar impact of temperature on $\mathrm{P}$ and $\mathrm{R}_{\mathrm{m}}$ was observed for mechanical pretreatment.

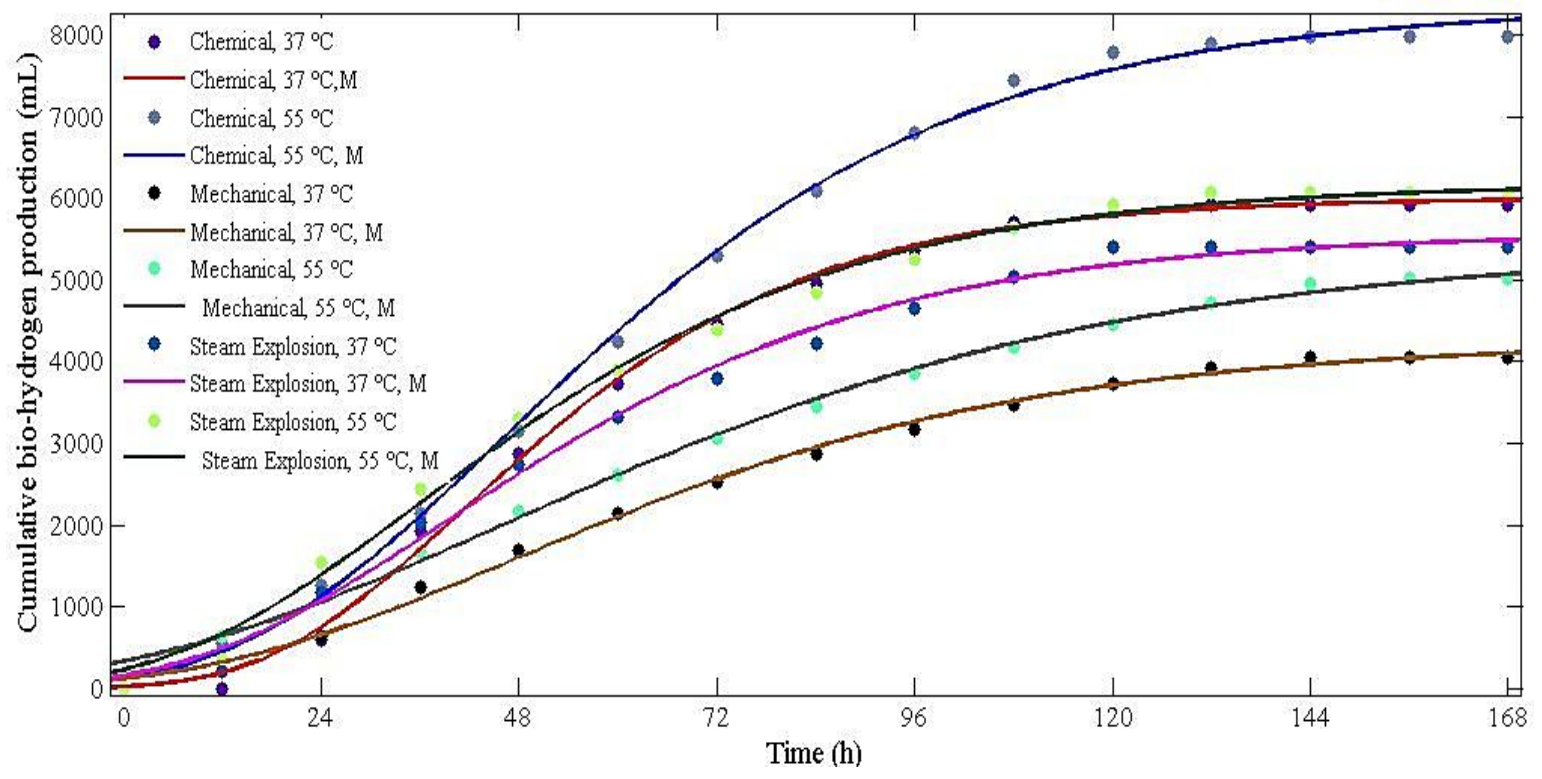

Figure 2. Cumulative bio-hydrogen production under tested treatments.

It was also observed that the P-values for thermophilic mechanical pretreatment and mesophilic steam explosion were close to each other, whereas the respective $R_{m}$ values for both treatments were much different from each other. One of the main reasons for such a difference in P-values is the lag phase $(\lambda)$, i.e., the $\lambda$ for thermophilic mechanical pretreatment $(1.271 \mathrm{~h})$ is smaller than the $\lambda$ observed 
for mesophilic steam explosion $(6.538 \mathrm{~h})$, which represented the early production of bio-hydrogen in the thermophilic reactor under mechanical pretreatment. The early start of bio-hydrogen production in thermophilic reactor under mechanical pretreatment continued till $156 \mathrm{~h}$ of incubation, whereas the production was closed after $120 \mathrm{~h}$ in the mesophilic reactor under steam explosion. Because of these two facts, the P-values for both reactors were close to each other, even after having a huge difference in $\mathrm{R}_{\mathrm{m}}$ values.

Table 1. Properties of rice straw under different pretreatments.

\begin{tabular}{cccc}
\hline Properties (\%) & Mechanical & Steam Explosion & Chemical \\
\hline Holocellulose & 66.79 & 56.92 & 54.53 \\
LCH & 76.51 & 70.64 & 61.51 \\
Lignin & 9.72 & 13.72 & 6.98 \\
Ash & 11.21 & 21.81 & 19.46 \\
TS & 92.05 & 20.53 & 90.49 \\
VS & 77.36 & 16.94 & 74.46 \\
\hline
\end{tabular}

$\mathrm{LCH}=$ lignin, cellulose, hemicellulose; Ash = Solid remaining after ignition; TS, total solids; VS , volatile solids.

Kinetic parameters can be used to derive the time $\left(t_{\max }\right)$ required to attain the maximum value of $R_{m}$. This can be done by taking the first derivative with respect to time of Equation (1) and comparing the results with zero [36]. The resultant equation is:

$$
t_{\max }=\lambda+\frac{P}{e \cdot R_{m}}
$$

By placing the kinetic parameters in Equation (1), the resultant $t_{\max }$ values are shown in Table 1. The increase in temperature decreased the $t_{\max }$ for mechanical pretreatment and steam explosion and increased it for chemical pretreatment. The $t_{\max }$ can be used as the hydraulic retention time (HRT) in continuous production of bio-hydrogen. As the $t_{\max }$ for steam explosion at $55^{\circ} \mathrm{C}$ is the smallest in all treatments, steam explosion is more suitable for continuous production processes.

The response surface methodology was opted for a better representation of the bio-hydrogen production with time. In the first step, a quadratic model was fit to the bio-hydrogen production data using false values for incubation time $\left(x_{1}:-3=24 \mathrm{~h} ; 3=168 \mathrm{~h}\right)$, pretreatment method $\left(x_{2}:-1=\right.$ mechanical, $0=$ steam explosion and $1=$ chemical $)$ and temperature $\left(x_{3}:-1=37^{\circ} \mathrm{C}\right.$ and $\left.1=55^{\circ} \mathrm{C}\right)$. The following equation was obtained:

$$
\begin{gathered}
Y=4202.5+705.42 x_{1}+487.5 x_{2}+228.75 x_{3}-93.33 x_{1}^{2}-332.5 x_{2}^{2}+158.75 x_{1} x_{2}-23.33 x_{1} x_{3}+26.25 x_{2} x_{3} \\
R^{2}=0.912 ; \mathrm{F}=414.56
\end{gathered}
$$

Here, $Y$ is the modeled cumulative bio-hydrogen production. The quadratic model developed has a high $\mathrm{F}$ value and can significantly explain $91.2 \%$ of the variability. The $2 \mathrm{D}$ contour plots developed for modeled bio-hydrogen production are shown in Figure 3. It was revealed from modeling that the impact of temperature during the first $24 \mathrm{~h}$ was the highest under chemical pretreatment and the lowest under steam explosion. This can be visualized in the contours by observing the variation in the size of the triangle filled with dark blue color (Figure 3). The decrease in bio-hydrogen production was observed first under mechanical pretreatment after $60 \mathrm{~h}$ of incubation, which became more prominent under mesophilic temperature after $108 \mathrm{~h}$. Such a change in bio-hydrogen production can be visualized by the area of the color distribution in surface plots or by observing the change in the width of contours. The decrease in modeled bio-hydrogen was observed after $72 \mathrm{~h}$ and $84 \mathrm{~h}$, which also became more protuberant after $120 \mathrm{~h}$ and $144 \mathrm{~h}$ of incubation at $37^{\circ} \mathrm{C}$ under steam explosion and chemical pretreatment, respectively. The decrease in actual bio-hydrogen production was also observed during the same span of time, but it was difficult to observe the noticeable change in bio-hydrogen 
production, as observed in contour and surface plots. As a whole, the 2D illustration of the modeled bio-hydrogen production provides a better representation, which is more helpful to understand the impact of pretreatment and temperature as compared to the line graphs developed.

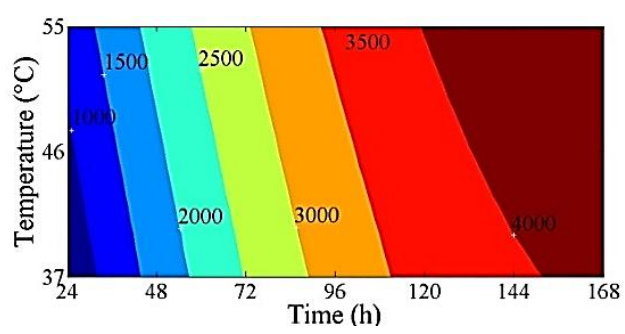

(a)

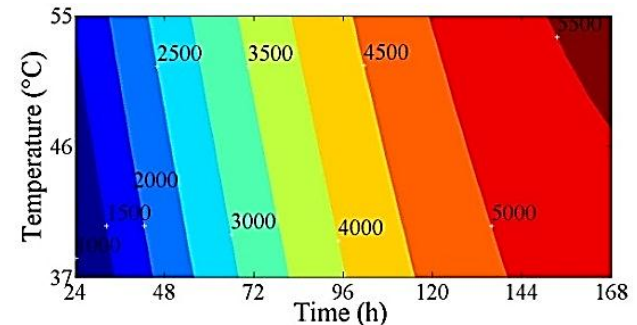

(b)

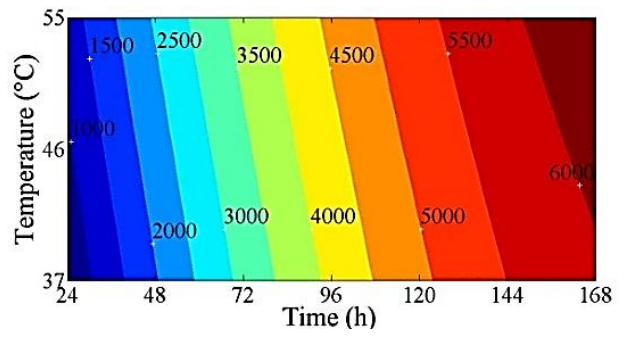

(c)

Figure 3. Modeled bio-hydrogen production: (a) mechanical pretreatment; (b) steam explosion; (c) chemical pretreatment.

\subsection{Bio-Hydrogen Yield}

The bio-hydrogen yield was calculated by dividing the $\mathrm{P}$ with initial volatile solid contents of the reactor $\left(\mathrm{VS}_{\text {fed }}\right)$. The impact of temperature was the same as observed on cumulative bio-hydrogen production, as the initial VS fed were the same for each treatment under both temperatures. The chemical treatment resulted in higher bio-hydrogen yield under both temperatures as compared to other treatments. It is clear from the Table 1 that the lignin content was decreased due to chemical treatment. The decrease in lignin content occurred in two steps. First, the lignin-carbohydrate complexes (LCCs) formed due chemical bonds among lignin and holocellulose being changed as the bonds were hydrolyzed by the saponification reaction and released holocellulose, which also increased the degradation of straw $[37,38]$. In the second stage, de-polymerization of lignin occurred and formed other substances that reduced the lignin content [15]. The cellulose released from LCCs was also affected by the $\mathrm{NaOH}$ used in the chemical treatment, which caused intramolecular and intermolecular changes [39]. Such changes resulted in decreased cellulose content, as well as made degradation easier for microbes. The same intramolecular and intermolecular degradation was also observed for hemicellulose because of the breakage and disruption of bonds during $\mathrm{NaOH}$ treatment, which ultimately reduced the hemicellulose (Table 1) [40]. On the other hand, steam explosion pretreatment increased the lignin content due to migration, re-condensation and re-localization of lignin onto outer surfaces, which also exposes the internal cellulose [41]. However, during this process, the crystalline structure of cellulose is preserved, while hemicellulose degraded and de-polymerized and resulted in higher holocellulose, as compared to chemical treatment [20]. This is the major difference in both pretreatments, which increased the bio-hydrogen yield from 10 to $15.30 \mathrm{~mL} / \mathrm{g} \mathrm{VS}_{\text {fed }}$ when the method was changed from steam explosion pretreatment to chemical pretreatment. Whereas, the mechanical treatment has no effect on the compositional properties, it reduced the crystalline nature of the cellulose, increased the active surface area, as well as increased the degree of polymerization [42]; which ultimately improved the hydrolysis of straw and the bio-hydrogen yield of $9.72 \mathrm{~mL} / \mathrm{VS}_{\text {fed }}$ 
obtained under thermophilic conditions. As a whole, the bio-hydrogen yields obtained in the present study are in agreement with the findings of Alimehdi [33].

The impact of the pretreatment method would be clearer if the yield were calculated on the removed fraction of volatile solids ( $\mathrm{VS}_{\text {removed }}$ ), as presented in Table 2. The increase in temperature from $37^{\circ} \mathrm{C}$ to $55^{\circ} \mathrm{C}$ increased the bio-hydrogen yield ( $\left(\mathrm{VS}_{\text {removed }}\right)$ by $21.48 \%, 6.03 \%$ and $9.34 \%$ and VS removal by $17.53 \%, 16.03 \%$ and $4.66 \%$ under chemical, steam explosion and mechanical pretreatment, respectively. The increase in temperature from $37^{\circ} \mathrm{C}$ to $55^{\circ} \mathrm{C}$ increased the degradation of cellulose by Clostridium thermocellum, which increased the bio-hydrogen yield, especially from rice straw under chemical treatment, as more cellulose was available under chemical treatment as compared to other tested treatments [43]. Apparently, the percentage increase in yield under mechanical pretreatment is higher than steam explosion, but if it is compared to the percentage of increase in VS removal, then steam explosion is more efficient than mechanical pretreatment. On the other hand, the mesophilic P-value $(5570 \mathrm{~mL}$ ) of steam explosion is 3.11\% higher than the thermophilic P-value $(5402 \mathrm{~mL})$ of mechanical pretreatment, but the corresponding bio-hydrogen yield $\left(\mathrm{VS}_{\text {removed }}\right)$ of steam explosion is $19.37 \%$ higher than said mechanical pretreatment, which also makes steam explosion more efficient then mechanical pretreatment. Similarly, the thermophilic P-value $(6181 \mathrm{~mL})$ of steam explosion is $2.8 \%$ higher than the mesophilic P-value $(6008 \mathrm{~mL})$ of chemical pretreatment, but the bio-hydrogen yield of mesophilic chemical pretreatment is $0.98 \%$ higher than thermophilic steam explosion. As a whole, chemical pretreatment has a high efficiency in terms of cumulative bio-hydrogen production and yield, as well as in terms of VS removal. Apart from this, it has the lowest energy consumption compared to the other two methods, as well as zero pollutant emission, because there was no washing involved during pretreatment. Still, the bio-hydrogen yield obtained in the present study can be further improved by replacing the sludge source, as well as combining the pretreatment methods, like alkaline with chemical for more effective degradation of lignocellulosic biomass [19,32].

Table 2. Kinetic parameters and bio-hydrogen yield.

\begin{tabular}{|c|c|c|c|c|c|c|c|c|}
\hline \multirow{2}{*}{ Pretreatment } & \multirow{2}{*}{ Temperature } & \multirow{2}{*}{$\frac{P}{(\mathrm{~mL})}$} & \multirow{2}{*}{$\begin{array}{c}R_{\mathrm{m}} \\
(\mathrm{mL} / \mathrm{h})\end{array}$} & \multirow{2}{*}{$\frac{\lambda}{(h)}$} & \multirow{2}{*}{$\begin{array}{l}t_{\max } \\
\text { (h) }\end{array}$} & \multirow{2}{*}{$R^{2}$} & \multicolumn{2}{|c|}{ Hydrogen Yield } \\
\hline & & & & & & & $\left(\mathrm{mL} / \mathrm{VS}_{\mathrm{fed}}\right)$ & $\left(\mathrm{mL} / \mathrm{VS}_{\text {removed }}\right)$ \\
\hline \multirow{2}{*}{ Mechanical } & $37^{\circ} \mathrm{C}$ & 4258 & 42.51 & 10.26 & 47.22 & 0.9973 & 7.66 & 36.62 \\
\hline & $55^{\circ} \mathrm{C}$ & 5402 & 44.73 & 1.27 & 45.84 & 0.9955 & 9.72 & 40.04 \\
\hline Steam & $37^{\circ} \mathrm{C}$ & 5570 & 66.78 & 6.53 & 37.32 & 0.9941 & 9.01 & 47.80 \\
\hline Explosion & $55^{\circ} \mathrm{C}$ & 6181 & 75.17 & 5.88 & 36.23 & 0.9948 & 10.00 & 50.68 \\
\hline \multirow{2}{*}{ Chemical } & $37^{\circ} \mathrm{C}$ & 6008 & 92.44 & 17.65 & 41.63 & 0.9977 & 11.00 & 51.18 \\
\hline & $55^{\circ} \mathrm{C}$ & 8361 & 96.5 & 14.36 & 46.33 & 0.9982 & 15.30 & 60.60 \\
\hline
\end{tabular}

\subsection{Change in $p H$}

There was a sudden drop in $\mathrm{pH}$ during the first $12 \mathrm{~h}$ of incubation, especially under mesophilic reactors [44]. The increase in temperature from $37{ }^{\circ} \mathrm{C}$ to $55^{\circ} \mathrm{C}$ decreased the initial drop in $\mathrm{pH}$, which also increased the bio-hydrogen production during $12 \mathrm{~h}$ of incubation (Figures 2 and 4) [45]. The mesophilic reactor under mechanical pretreatment has a higher drop in $\mathrm{pH}$ during the first $12 \mathrm{~h}$ of incubation, but in next $12 \mathrm{~h}$, the drop in $\mathrm{pH}$ was less compared to other mesophilic reactors. On the other hand, the drop in $\mathrm{pH}$ under steam explosion pretreatment was least effected by an increase in temperature from $37^{\circ} \mathrm{C}$ to $55^{\circ} \mathrm{C}$ till $60 \mathrm{~h}$ of incubation, after which, mesophilic $\mathrm{pH}$ was fluctuating between 5.7 and 5.8 till $120 \mathrm{~h}$, and thermophilic $\mathrm{pH}$ decreased to 5.7 till $144 \mathrm{~h}$ of incubation; whereas, reactors under chemical pretreatment have the least $\mathrm{pH}$ drop during $12 \mathrm{~h}$ of incubation and the impact of an increase in temperature within the experimental range was higher than steam explosion treatment, but less than mechanical. The difference between $\mathrm{pH}$ under both temperatures kept on increasing till $72 \mathrm{~h}$ of incubation, after which, the mesophilic $\mathrm{pH}$ was stable at 5.9 till bio-hydrogen production was ceased at $120 \mathrm{~h}$, and the thermophilic drop in $\mathrm{pH}$ continued till bio-hydrogen production was 
ceased at $144 \mathrm{~h}$ of incubation. Although the $\mathrm{pH}$ at which the bio-hydrogen production ceased for chemical pretreatment was the same under both temperatures ( $\mathrm{pH} 5.9$ ), the incubation time at which the bio-hydrogen production was ceased was different. On the other hand, the final $\mathrm{pH}$ at the end of incubation was also different, as the $\mathrm{pH}$ again started to decrease after bio-hydrogen production was ceased in the mesophilic reactor. The thermophilic $\mathrm{pH}$ at which the bio-hydrogen production ceased in other treatments was higher than the mesophilic $\mathrm{pH}$. As a whole, $\mathrm{pH}$ from $6.7 \pm 0.1$ to $5.8 \pm 0.1$ and $7.1 \pm 0.1$ to $5.8 \pm 0.1$ was found suitable for co-digestion under mesophilic and thermophilic conditions, respectively.

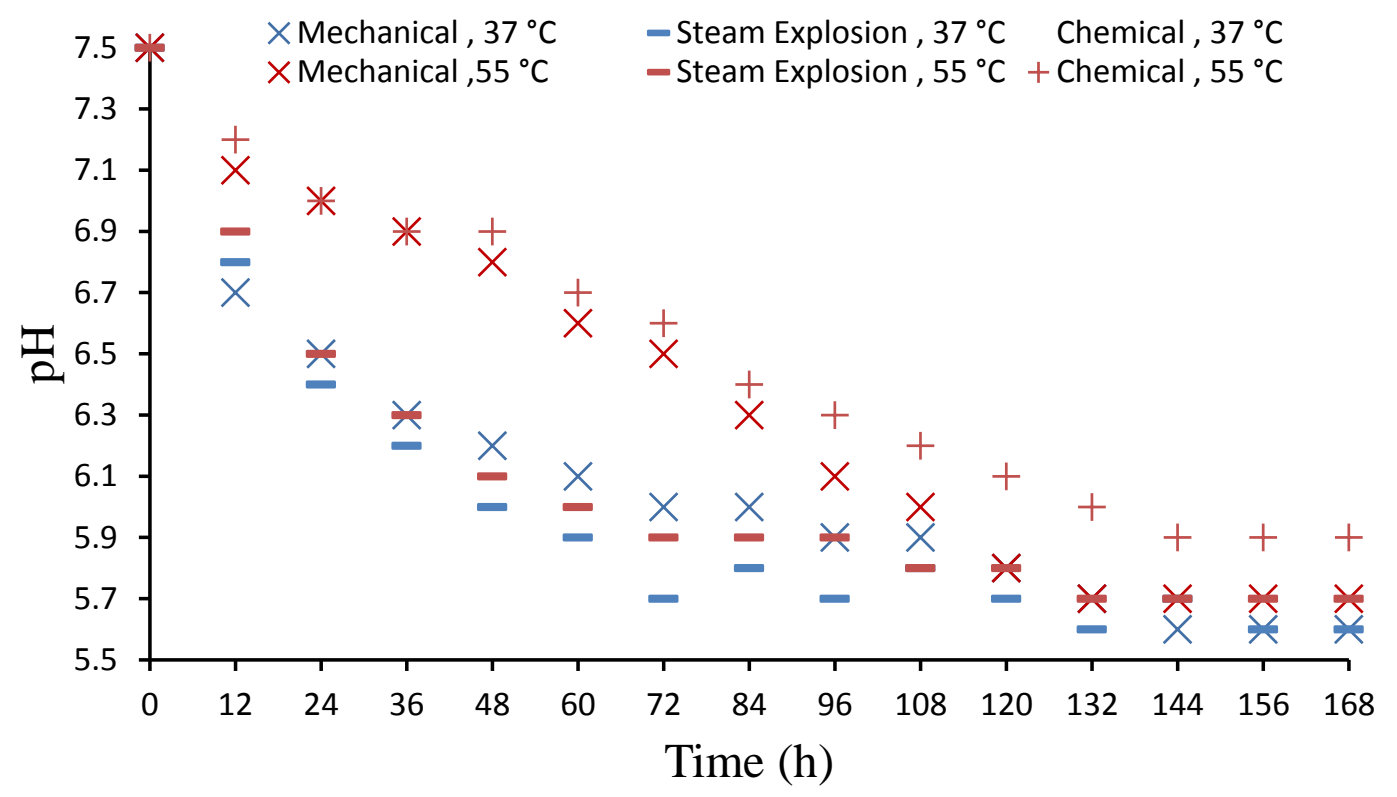

Figure 4. Drop in $\mathrm{pH}$ during incubation.

Quadratic modeling was done on $\mathrm{pH}$ data in the same way opted for bio-hydrogen production, and the following equation was obtained:

$$
\begin{gathered}
Y=5.68-0.17 x_{1}+0.07 x_{2}+0.12 x_{3}+0.03 x_{1}^{2}+0.45 x_{2}^{2}-0.13 x_{3}^{2}+0.01 x_{1} x_{2}-0.03 x_{1} x_{3}-0.03 x_{2} x_{3} \\
R^{2}=0.8578 ; \mathrm{F}=241.37
\end{gathered}
$$

Here, $Y$ represents the $\mathrm{pH}$ within experimental conditions. The model explained the experimental results well for mechanical and chemical treatment, but not for steam explosion treatment, as the predicted values were $0.2-0.3 \mathrm{pH}$ lesser than actual, but the trend was the same. Still, the $R^{2}$ value is acceptable in order to predict $\mathrm{pH}$. Figure 5 represents the 2D plots by using Equation (4). The drop in $\mathrm{pH}$ represented a similar trend under mechanical and steam explosion till $96 \mathrm{~h}$ of incubation, whereas the variation was high under chemical treatment till $108 \mathrm{~h}$ of incubation. Mostly, the bio-hydrogen production was observed till $144 \mathrm{~h}$ of incubation, and the modeled values represented the same range of $\mathrm{pH}$ as observed experimentally. After $120 \mathrm{~h}$, the modeled variation in $\mathrm{pH}$ was the least, which was in agreement with the actual results. 


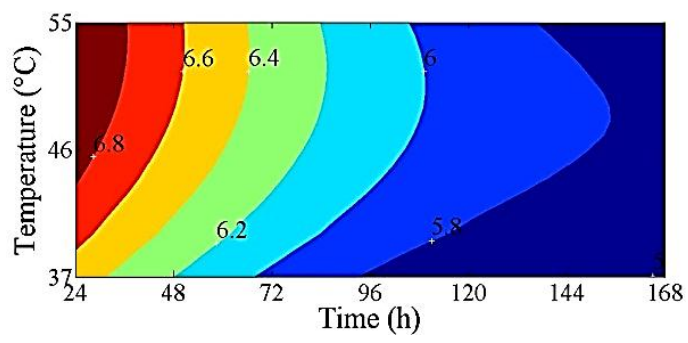

(a)

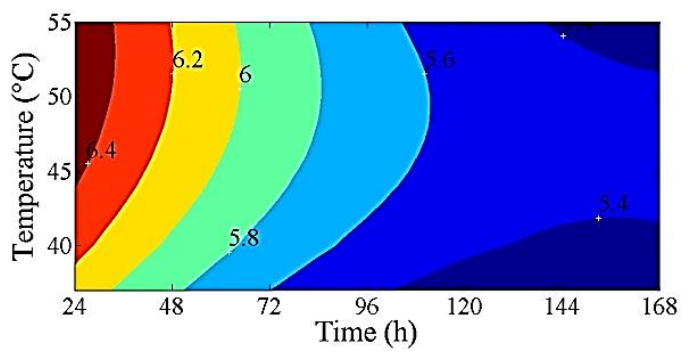

(b)

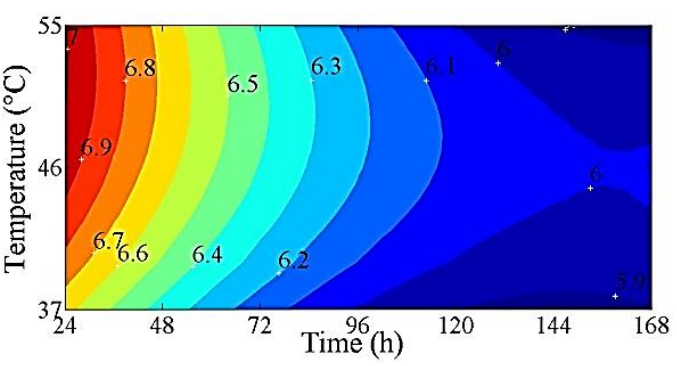

(c)

Figure 5. Modeled drop in $\mathrm{pH}$ : (a) mechanical pretreatment; (b) steam explosion; (c) chemical pretreatment.

\subsection{VFA Production under Tested Pretreatment}

In the present study, heat shocked sludge was used for co-digestion with pretreated straw, and it was observed that the VFA contents increased with an increase in time $(168 \mathrm{~h})$, which was in agreement with the finding of Kim [46]. The effect of pretreatment, temperature and time on VFA is represented in Figure 6. The highest experimental VFA at the end of incubation was observed in the mesophilic reactor under mechanical pretreatment. The increase in temperature decreased the VFA content for mechanical and steam explosion treatments, as also observed by Gadow [45]. The VFA contents were initially higher in the mesophilic rector under chemical pretreatment, but during $48 \mathrm{~h}-72 \mathrm{~h}$ of incubation, thermophilic VFA contents became higher. This was the same duration in which the bio-hydrogen production was increased dramatically in thermophilic reactors as compared to the mesophilic reactor under chemical pretreatment (Figure 2). As a whole, the VFA production rate was higher till $72 \mathrm{~h}$, which was the same duration in which bio-hydrogen production was also higher, after which, VFA and the bio-hydrogen production rate both started to decrease. However, there was a sudden increase in VFA contents in the mesophilic reactor under mechanical pretreatment during $120 \mathrm{~h}-144 \mathrm{~h}$ of incubation. For the same duration, the VFA production was not so high in the thermophilic reactor under the same treatment, but bio-hydrogen production was much higher in the thermophilic reactor. The higher VFA contents can be inhibitory to the growth of bacteria, as they cause unfavorable physical changes in the cell and excessive energy is required to pump ions [25]. Such high energy is available at elevated temperatures, which increased the yield at elevated temperatures, as observed in the present study [47-49].

The following equation was obtained for VFA as a result of quadratic modeling:

$$
\begin{gathered}
Y=2683.54+259.387 x_{1}-166.82 x_{2}-276.2 x_{2}-11.81 x_{1}^{2}-268.75 x_{2}^{2}+10.99 x_{3}^{2}-98.06 x_{1} x_{2}-38.68 x_{1} x_{3}+66.41 x_{2} x_{3} \\
R^{2}=0.8378 ; \mathrm{F}=206.58
\end{gathered}
$$

The resultant 2D plots for VFA are shown in Figure 7. It is clear that the VFA contents were high at the low modeled temperature range $\left(37^{\circ} \mathrm{C}\right)$ at the end of incubation, as observed experimentally under mechanical pretreatment (Figure 7a). The variation in VFA contents decreased with an increase in temperature and incubation time under mechanical and steam explosion treatments, but the 
trend of variation was not the same under both treatments (Figure 7a,b). The VFA contents were almost the same at $96 \mathrm{~h}, 37^{\circ} \mathrm{C}$ and $168 \mathrm{~h}, 55^{\circ} \mathrm{C}$ under mechanical pretreatment and $60 \mathrm{~h}, 37^{\circ} \mathrm{C}$ and $168 \mathrm{~h}, 55^{\circ} \mathrm{C}$ under steam explosion, which represent higher variations of VFA in the case of steam explosion as compared to mechanical pretreatment. On the other hand, VFA production under chemical treatment was different than the other two tested treatments (Figure 7c). The VFA contents were higher under the mesophilic condition till $60 \mathrm{~h}$ of incubation, after which thermophilic VFA started to increase. After $120 \mathrm{~h}$ of incubation, the VFA variation increased with an increase in temperature, and VFA contents at $168 \mathrm{~h}, 37^{\circ} \mathrm{C}$ and $144 \mathrm{~h}, 55^{\circ} \mathrm{C}$ were almost same under chemical pretreatment. This represented the least effect of temperature under chemical pretreatment as compared to the other two tested treatments.

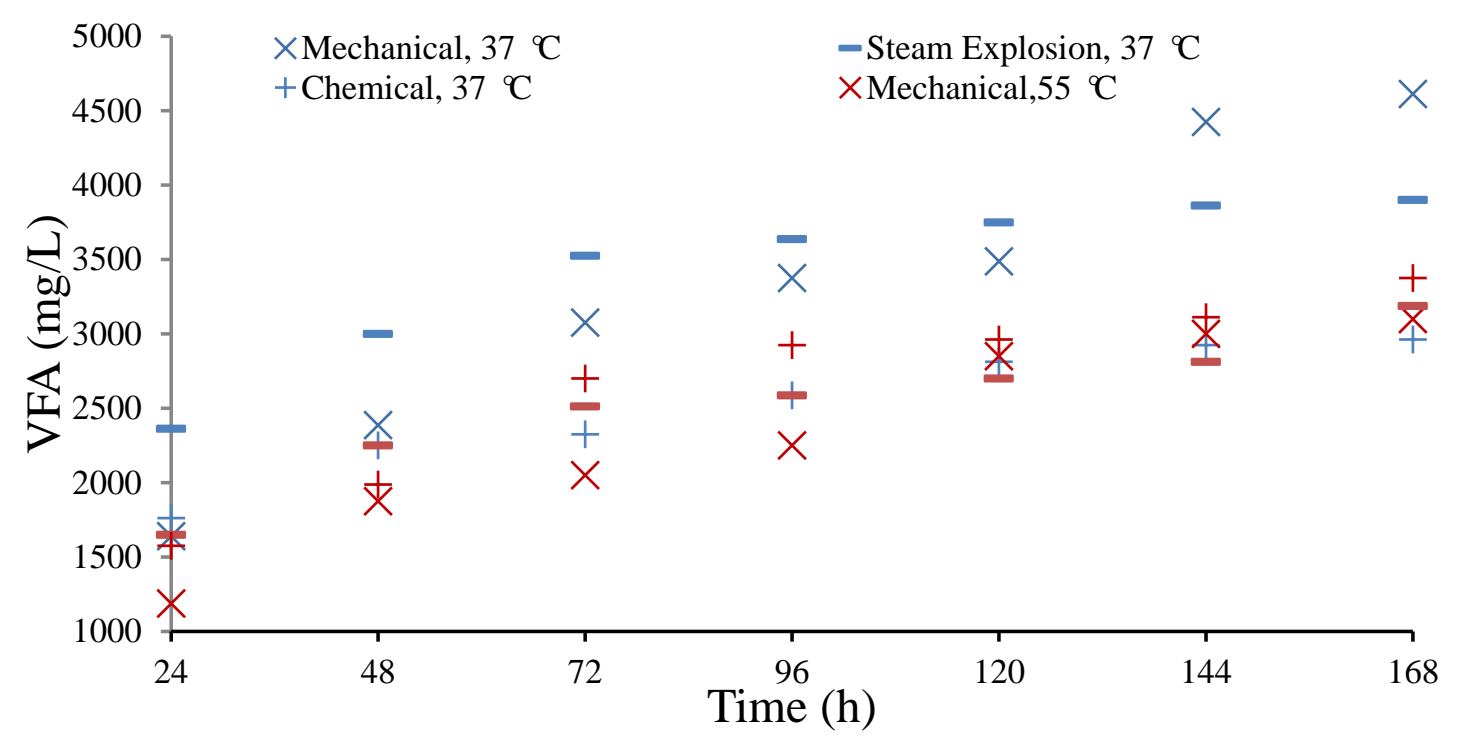

Figure 6. Volatile fatty acids (VFA) trend under various treatments.

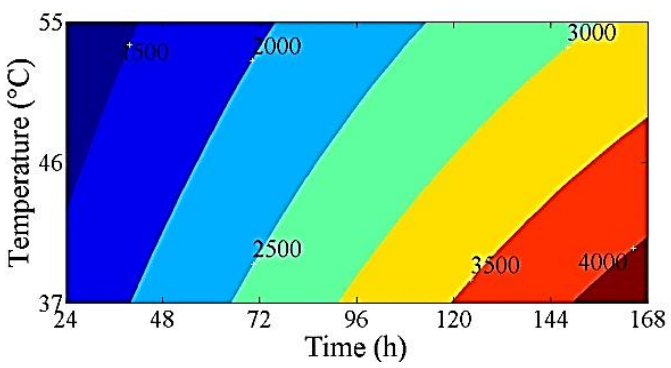

(a)

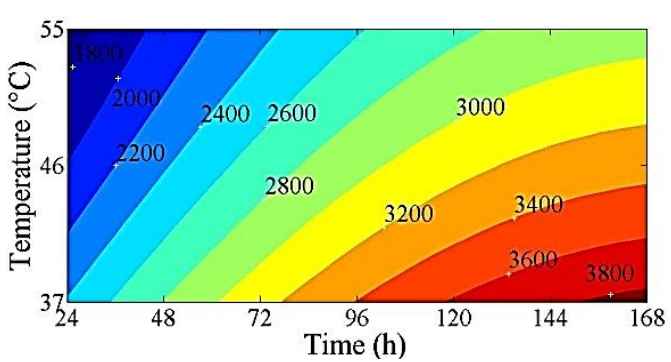

(b)

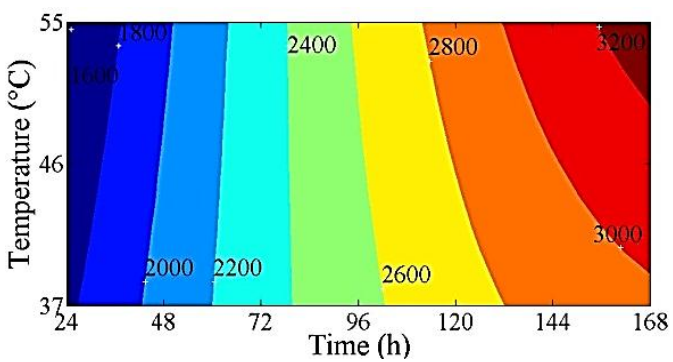

(c)

Figure 7. Modeled VFA: (a) mechanical pretreatment; (b) steam explosion; (c) chemical retreatment. 


\section{Conclusions}

The effect of mechanical, steam explosion and chemical pretreatments on the lignocellulosic properties of rice straw, as well as on the bio-hydrogen production potential of rice straw when co-digested with heat shocked sludge was studied under mesophilic and thermophilic conditions. The chemical pretreatment was observed to be the most effective way to reduce holocellulose contents, as well as decreasing the lignin contents of rice straw, which ultimately produced more bio-hydrogen under co-digestion as compared to the other two tested treatments. The increase in temperature from mesophilic to thermophilic conditions found an effective way to enhance bio-hydrogen production through co-digestion, and the highest experimental yield of $60.6 \mathrm{~mL} / \mathrm{g}$ $\mathrm{VS}_{\text {removed }}$ was obtained from chemical pretreatment under thermophilic conditions. The drop in $\mathrm{pH}$ was observed during the incubation $\mathrm{pH}$ from $6.7 \pm 0.1$ to $5.8 \pm 0.1$ and $7.1 \pm 0.1$ to $5.8 \pm 0.1$ to be suitable for bio-hydrogen production through co-digestion under mesophilic and thermophilic conditions, respectively. The 2D plots developed by the response surface methodology provided better representation of the experimental outcomes under various sets of treatments. As a whole, chemical pretreatment is recommended for rice straw, because of the higher bio-hydrogen yield through co-digestion, better $\mathrm{pH}$ environment and zero pollutant emission.

Supplementary Materials: The following are available online at www.mdpi.com/1996-1073/9/3/198/s1. Figure S1. Steps for mechanical treatment. Figure S2. Preparation for steam explosion treatment. Figure S3. Chemical pretreatment. Figure S4. Treated rice straw and sludge in the anaerobic bioreactor. Table S1. Average bio-hydrogen production.

Acknowledgments: We thank Chen Kunjie for providing lab facilities; Fang Himin, Huang Yu Ping and Kang Jin Bao for their help during lab work; Farman Ali Chandio and Fiaz Ahmad for helpful discussions and critical reviews. We also thank Uzma Sattar for improving the standard of the English. We extend our thanks to Higher Education Commission, Pakistan, the China Scholarship council and the College of Engineering, Nanjing Agricultural University, Nanjing, for supporting and providing research facilities for this study.

Author Contributions: Asma Sattar and Chaudhry Arslan designed the research and performed all of the lab work. Changying Ji provided the financial and technical support for designing and conducting the research, as well as supervised the whole research process. Sumiyya Sattar and Haroon Rashid developed and customized the 2D surface plots and assisted in the manuscript preparation. Irshad Ali Mari assisted the lab work and analysis. Fariha Ilyas performed the statistical analysis. Asma Sattar and Chaudhry Arslan wrote the manuscript with comments from all authors, and Asma Sattar finalized the manuscript under the supervision and guidelines of Changying Ji.

Conflicts of Interest: The authors declare no conflict of interest.

\section{References}

1. Ni, M.; Leung, D.Y.; Leung, M.K.; Sumathy, K. An overview of hydrogen production from biomass. Fuel Process. Technol. 2006, 87, 461-472. [CrossRef]

2. Yuan, Z.; Wu, C.; Huang, H.; Lin, G. Research and development on biomass energy in china. Int. J. Energy Technol. Policy 2002, 1, 108-144. [CrossRef]

3. Kadam, K.L.; Forrest, L.H.; Jacobson, W.A. Rice straw as a lignocellulosic resource: Collection, processing, transportation, and environmental aspects. Biomass Bioenergy 2000, 18, 369-389. [CrossRef]

4. Singh, A.; Sevda, S.; Abu Reesh, I.M.; Vanbroekhoven, K.; Rathore, D.; Pant, D. Biohydrogen production from lignocellulosic biomass: Technology and sustainability. Energies 2015, 8, 13062-13080. [CrossRef]

5. Claassen, P.; Van Lier, J.; Contreras, A.L.; Van Niel, E.; Sijtsma, L.; Stams, A.; De Vries, S.; Weusthuis, R. Utilisation of biomass for the supply of energy carriers. Appl. Microbiol. Biotechnol. 1999, 52, 741-755. [CrossRef]

6. Nath, K.; Das, D. Improvement of fermentative hydrogen production: Various approaches. Appl. Microbiol. Biotechnol. 2004, 65, 520-529. [CrossRef] [PubMed]

7. Hawkes, F.; Dinsdale, R.; Hawkes, D.; Hussy, I. Sustainable fermentative hydrogen production: Challenges for process optimisation. Int. J. Hydrog. Energy 2002, 27, 1339-1347. [CrossRef]

8. Lynd, L.R.; Van Zyl, W.H.; McBride, J.E.; Laser, M. Consolidated bioprocessing of cellulosic biomass: An update. Curr. Opin. Biotechnol. 2005, 16, 577-583. [CrossRef] [PubMed] 
9. Mosier, N.; Wyman, C.; Dale, B.; Elander, R.; Lee, Y.; Holtzapple, M.; Ladisch, M. Features of promising technologies for pretreatment of lignocellulosic biomass. Bioresour. Technol. 2005, 96, 673-686. [CrossRef] [PubMed]

10. Kratky, L.; Jirout, T. Biomass size reduction machines for enhancing biogas production. Chem. Eng. Technol. 2011, 34, 391-399. [CrossRef]

11. Sun, Y.; Cheng, J. Hydrolysis of lignocellulosic materials for ethanol production: A review. Bioresour. Technol. 2002, 83, 1-11. [CrossRef]

12. Weil, J.; Sarikaya, A.; Rau, S.-L.; Goetz, J.; Ladisch, C.M.; Brewer, M.; Hendrickson, R.; Ladisch, M.R. Pretreatment of yellow poplar sawdust by pressure cooking in water. Appl. Biochem. Biotechnol. 1997, 68, 21-40. [CrossRef]

13. Zheng, Y.; Zhao, J.; Xu, F.; Li, Y. Pretreatment of lignocellulosic biomass for enhanced biogas production. PrECS 2014, 42, 35-53. [CrossRef]

14. Yasuda, M.; Kurogi, R.; Tsumagari, H.; Shiragami, T.; Matsumoto, T. New approach to fuelization of herbaceous lignocelluloses through simultaneous saccharification and fermentation followed by photocatalytic reforming. Energies 2014, 7, 4087-4097. [CrossRef]

15. He, Y.; Pang, Y.; Liu, Y.; Li, X.; Wang, K. Physicochemical characterization of rice straw pretreated with sodium hydroxide in the solid state for enhancing biogas production. Energy Fuels 2008, 22, 2775-2781. [CrossRef]

16. Fang, H.H.; Li, C.; Zhang, T. Acidophilic biohydrogen production from rice slurry. Int. J. Hydrog. Energy 2006, 31, 683-692. [CrossRef]

17. Oh, S.-E.; Van Ginkel, S.; Logan, B.E. The relative effectiveness of $\mathrm{pH}$ control and heat treatment for enhancing biohydrogen gas production. Environ. Sci. Technol. 2003, 37, 5186-5190. [CrossRef] [PubMed]

18. Li, D.; Chen, H. Biological hydrogen production from steam-exploded straw by simultaneous saccharification and fermentation. Int. J. Hydrog. Energy 2007, 32, 1742-1748. [CrossRef]

19. He, L.; Huang, H.; Lei, Z.; Liu, C.; Zhang, Z. Enhanced hydrogen production from anaerobic fermentation of rice straw pretreated by hydrothermal technology. Bioresour. Technol. 2014, 171, 145-151. [CrossRef] [PubMed]

20. Ibrahim, M.M.; El-Zawawy, W.K.; Abdel-Fattah, Y.R.; Soliman, N.A.; Agblevor, F.A. Comparison of alkaline pulping with steam explosion for glucose production from rice straw. Carbohydr. Polym. 2011, 83, 720-726. [CrossRef]

21. Nathao, C.; Sirisukpoka, U.; Pisutpaisal, N. Production of hydrogen and methane by one and two stage fermentation of food waste. Int. J. Hydrog. Energy 2013, 38, 15764-15769. [CrossRef]

22. Li, C.; Fang, H.H. Fermentative hydrogen production from wastewater and solid wastes by mixed cultures. Crit. Rev. Environ. Sci. Technol. 2007, 37, 1-39. [CrossRef]

23. Reungsang, A.; Sreela-or, C. Bio-hydrogen production from pineapple waste extract by anaerobic mixed cultures. Energies 2013, 6, 2175-2190. [CrossRef]

24. Sattar, A.; Arslan, C.; Ji, C.; Chen, K.; Nasir, A.; Fang, H.; Umair, M. Optimizing the physical parameters for bio-hydrogen production from food waste co-digested with mixed consortia of clostridium. J. Renew. Sustain. Energy 2016, 8, 013107. [CrossRef]

25. Arslan, C.; Sattar, A.; Ji, C.; Sattar, S.; Yousaf, K.; Hashim, S. Optimizing the impact of temperature on bio-hydrogen production from food waste and its derivatives under no $\mathrm{pH}$ control using statistical modelling. BGeo 2015, 12, 6503-6514. [CrossRef]

26. APHA. Standard Methods for the Examination of Water and Wastewater, 25th ed.; American Public Health Association: Washington, DC, USA, 2005; pp. 94-100.

27. Arslan, C.; Sattar, A.; Changying, J.; Nasir, A.; Ali Mari, I.; Zia Bakht, M. Impact of pH management interval on biohydrogen production from organic fraction of municipal solid wastes by mesophilic thermophilic anaerobic codigestion. BioMed. Res. Int. 2015, 2015. [CrossRef] [PubMed]

28. Ververis, C.; Georghiou, K.; Danielidis, D.; Hatzinikolaou, D.; Santas, P.; Santas, R.; Corleti, V. Cellulose, hemicelluloses, lignin and ash content of some organic materials and their suitability for use as paper pulp supplements. Bioresour. Technol. 2007, 98, 296-301. [CrossRef] [PubMed]

29. Ramos, C.; Buitrón, G.; Moreno-Andrade, I.; Chamy, R. Effect of the initial total solids concentration and initial $\mathrm{pH}$ on the bio-hydrogen production from cafeteria food waste. Int. J. Hydrog. Energy 2012, 37, 13288-13295. [CrossRef] 
30. Kim, S.-H.; Han, S.-K.; Shin, H.-S. Optimization of continuous hydrogen fermentation of food waste as a function of solids retention time independent of hydraulic retention time. Process. Biochem. 2008, 43, 213-218. [CrossRef]

31. Jo, J.H.; Lee, D.S.; Park, D.; Choe, W.-S.; Park, J.M. Optimization of key process variables for enhanced hydrogen production by enterobacter aerogenes using statistical methods. Bioresour. Technol. 2008, 99, 2061-2066. [CrossRef] [PubMed]

32. Kim, M.; Liu, C.; Noh, J.-W.; Yang, Y.; Oh, S.; Shimizu, K.; Lee, D.-Y.; Zhang, Z. Hydrogen and methane production from untreated rice straw and raw sewage sludge under thermophilic anaerobic conditions. Int. J. Hydrog. Energy 2013, 38, 8648-8656. [CrossRef]

33. Alemahdi, N.; Man, H.C.; Nasirian, N.; Yang, Y. Enhanced mesophilic bio-hydrogen production of raw rice straw and activated sewage sludge by co-digestion. Int. J. Hydrog. Energy 2015, 40, 16033-16044. [CrossRef]

34. Shin, H.-S.; Youn, J.-H.; Kim, S.-H. Hydrogen production from food waste in anaerobic mesophilic and thermophilic acidogenesis. Int. J. Hydrog. Energy 2004, 29, 1355-1363. [CrossRef]

35. Chen, C.-C.; Chuang, Y.-S.; Lin, C.-Y.; Lay, C.-H.; Sen, B. Thermophilic dark fermentation of untreated rice straw using mixed cultures for hydrogen production. Int. J. Hydrog. Energy 2012, 37, 15540-15546. [CrossRef]

36. Chang, A.C.; Tu, Y.-H.; Huang, M.-H.; Lay, C.-H.; Lin, C.-Y. Hydrogen production by the anaerobic fermentation from acid hydrolyzed rice straw hydrolysate. Int. J. Hydrog. Energy 2011, 36, 14280-14288. [CrossRef]

37. Yang, S. Plant Fiber Chemistry; China Light Industry Press: Beijing, China, 2001; pp. 176-182. (In Chinese)

38. Durot, N.; Gaudard, F.; Kurek, B. The unmasking of lignin structures in wheat straw by alkali. Phytochemistry 2003, 63, 617-623. [CrossRef]

39. Lu, J.; Shi, S.; Yang, R.; Niu, M.; Song, W. Modification of reed cellulose microstructure and it change in enzymatic hydrolysis of reed pulp. Trans. China Pulp. Pap. 2005, 20, 85-90. (In Chinese)

40. Sun, X.F.; Sun, R.; Tomkinson, J.; Baird, M. Preparation of sugarcane bagasse hemicellulosic succinates using nbs as a catalyst. Carbohydr. Polym. 2003, 53, 483-495. [CrossRef]

41. Selig, M.J.; Viamajala, S.; Decker, S.R.; Tucker, M.P.; Himmel, M.E.; Vinzant, T.B. Deposition of lignin droplets produced during dilute acid pretreatment of maize stems retards enzymatic hydrolysis of cellulose. Biotechnol. Prog. 2007, 23, 1333-1339. [CrossRef] [PubMed]

42. Hendriks, A.; Zeeman, G. Pretreatments to enhance the digestibility of lignocellulosic biomass. Bioresour. Technol. 2009, 100, 10-18. [CrossRef] [PubMed]

43. Levin DB, I.R.; Cicek, N.; Sparling, R. Hydrogen production by clostridium thermocellum 27,405 from cellulosic biomass substrates. Int. J. Hydrog. Energy 2006, 31, 1496-1503. [CrossRef]

44. Li, Y.; Zhang, R.; He, Y.; Liu, X.; Chen, C.; Liu, G. Thermophilic solid-state anaerobic digestion of alkaline-pretreated corn stover. Energy Fuels 2014, 28, 3759-3765. [CrossRef]

45. Gadow, S.; Li, Y.-Y.; Liu, Y. Effect of temperature on continuous hydrogen production of cellulose. Int. J. Hydrog. Energy 2012, 37, 15465-15472. [CrossRef]

46. Kim, M.; Yang, Y.; Morikawa-Sakura, M.S.; Wang, Q.; Lee, M.V.; Lee, D.-Y.; Feng, C.; Zhou, Y.; Zhang, Z. Hydrogen production by anaerobic co-digestion of rice straw and sewage sludge. Int. J. Hydrog. Energy 2012, 37, 3142-3149. [CrossRef]

47. Gottschalk, G. Bacterial Metabolism, 2nd ed.; Springer: New York, NY, USA, 1986.

48. Zoetemeyer, R.J.; Cohen, A.; Boelhouwer, C. Product inhibition in the acid forming stage of the anaerobic digestion process. Water Res. 1982, 16, 633-639. [CrossRef]

49. Switzenbaum, G.-G.E.; Hickey, R.F. Monitoring of the anaerobic methane fermentation process. Enzyme microbial technology. Enzyme Microb. Technol. 1990, 12, 722-730. [CrossRef]

(C) 2016 by the authors; licensee MDPI, Basel, Switzerland. This article is an open access article distributed under the terms and conditions of the Creative Commons by Attribution (CC-BY) license (http://creativecommons.org/licenses/by/4.0/). 